\title{
Ageing does not influence the sleep-related decrease in the hypercapnic ventilatory response
}

\author{
H.A.K. Browne*, L. Adams*, ${ }^{*}$, A.K. Simonds*, M.J. Morrell*,\#
}

Ageing does not influence the sleep-related decrease in the hypercapnic ventilatory response. H.A.K. Browne, L. Adams, A.K. Simonds, M.J. Morrell. (C)ER Journals Ltd 2003.

ABSTRACT: In young people, a sleep-related reduction in the gain of the ventilatory chemoreflex feedback loop occurs; in the elderly, it has been reported that no sleeprelated reduction occurs. A relatively high loop gain could contribute to periodic breathing and central sleep apnoea in the elderly. This study tested the hypothesis that ageing is associated with a reduction in the magnitude of the sleep-related decrease in the hypercapnic ventilatory response (HCVR).

The HCVR was measured using a steady state method, awake and asleep, in groups $(\mathrm{n}=10)$ of elderly (66-81 yrs) and young (23-35 yrs) nonapnoeics. Upper airway resistance was maintained close to wakefulness levels using continuous positive airway pressure (mean sleep-related increase in resistance: elderly $1.6 \pm 1.2 \mathrm{cmH}_{2} \mathrm{O} \cdot \mathrm{L} \cdot \mathrm{s}^{-1}$, young $\left.1.2 \pm 0.8 \mathrm{cmH}_{2} \mathrm{O} \cdot \mathrm{L} \cdot \mathrm{s}^{-1}\right)$.

The sleep-related decrease in the HCVR was similar in the elderly and young groups (elderly: wake $0.14 \pm 0.06$ and sleep $0.06 \pm 0.02 \mathrm{~L} \cdot \mathrm{min}^{-1} \cdot \mathrm{kPa}$ and young, wake $0.19 \pm 0.07$ and sleep $0.10 \pm 0.04 \mathrm{~L} \cdot \mathrm{min}^{-1} \cdot \mathrm{kPa}$ ).

Ageing per se was shown not to change the magnitude of the sleep-related decrease in hypercapnic ventilatory response. The authors speculate that age-related changes in the hypercapnic ventilatory response are unlikely to contribute to the increased prevalence of central sleep apnoea in the elderly.

Eur Respir J 2003; 21: 523-529.
*National Heart and Lung Institute, Imperial College School of Medicine, Charing Cross Campus, and "Royal Brompton Hospital, London, UK. School of Physiotherapy and Exercise Science, Griffith University, Gold Coast, Australia.

Correspondence: M.J. Morrell, Sleep and Ventilation Unit, Royal Brompton Hospital, Sydney Street, London, SW3 6NP, UK.

Fax: 442073518911

E-mail: m.morrell@ic.ac.uk

Keywords: Ageing, carbon dioxide, control of breathing, sleep, sleep apnoea

Received: May 102002

Accepted after revision: November 26 2002

A Welcome Trust Research Career Development Fellowship in Basic Biomedical Science awarded to M.J. Morrell supported this work
Sleep is associated with a decrease in the hypercapnic ventilatory response (HCVR) [1, 2]. This decrease may be an important factor in the maintenance of stable breathing during sleep, as it reduces the gain of the ventilatory chemoreflex feedback loop [3]. Studies in congestive heart failure (CHF) patients and idiopathic central sleep apnoea (CSA) patients support this concept. CHF patients with a high HCVR are more likely to have periodic breathing compared to those with a normal response [4] and CSA patients have a two-fold increase in the HCVR when awake compared to normal controls [5].

In the elderly, the prevalence of sleep apnoea is increased and the proportion of CSA is greater, compared to younger people [6-9]. The elderly also have a decreased HCVR during wakefulness [10-12]. On the face of it, these observations do not support the idea that the age-related increase in CSA is due to a higher gain of the chemoreflex loop. However, intriguingly, the only study to have measured the HCVR in elderly people during sleep, did not find a sleep-related reduction in the HCVR [13]. If the ageing process does result in a relatively high chemosensitivity during sleep this could result in respiratory instability at sleep onset and be the explanation for the increased prevalence of CSA in the elderly.

The authors have previously found elderly, nonapnoeic subjects to have a greater sleep-related increase in upper airway resistance (UAR) and arousal frequency compared to younger subjects $[14,15]$. The present study takes these potentially confounding factors into account and, specifically, tests the hypothesis that ageing is associated with a reduction in the magnitude of the sleep-related decrease in the HCVR. Groups of healthy, elderly and young nonapnoeic subjects, matched for body mass index (BMI), were studied during wakefulness, at sleep-onset and during stable nonrapid eye movement (NREM) sleep. A steady state method was used to measure the HCVR. The sleep-related increases in UAR were controlled for using continuous positive airway pressure (CPAP) $[16,17]$. The authors validated their method of testing the HCVR in the presence of CPAP prior to this study.

\section{Methods}

Ten healthy elderly subjects (aged 66-81 yrs, nine males) were recruited from the general population. Selection criteria were: no history of respiratory, cardiovascular or neurological disease; no known sleep apnoea; and forced vital capacity and forced expiratory volume in one second $>80 \%$ of their predicted value [18]. Ten healthy younger control subjects (aged 23-35 yrs, six males) were recruited using the same criteria. Emphasis was placed on carefully matching the groups for BMI. The experimental protocol was approved by the local ethics committee.

\section{Measurements}

Overnight polysomnography (two electroencephalograms (EEG), two electro-oculograms (EOG), submental muscle 
electromyogram (EMG), chest wall and abdominal movements, oral/nasal airflow, arterial oxygen saturation, and tracheal sounds (Sleeplab 1000p; Jaeger, Warwick UK)) was performed to confirm the absence of sleep apnoea (an apnoea/ hypopnoea index $<10$ events $\cdot \mathrm{h}^{-1}$ ) and a sleeping basal arterial oxygen saturation $\left(\mathrm{Sa}, \mathrm{O}_{2}\right)$ of $>90 \%$.

The sleeping HCVR was measured during a second sleep study, when UAR was maintained at wakefulness levels using CPAP. Sleep state was recorded as before. Airflow was measured using a pneumotachometer (Model 3700; Hans Rudolph, Kansas City, MO, USA) and differential pressure transducer (MP45 $\pm 2 \mathrm{cmH}_{2} \mathrm{O}$; Validyne, Northridge, CA, USA) attached via a full facemask (B\&D Electromedical, Stratfordupon-Avon, Warwickshire, UK). Respired carbon dioxide $\left(\mathrm{CO}_{2}\right)$ concentrations were determined using an infrared gas analyser sampling from a nasal probe (Capnograph; PK Morgan Ltd, Rainham, UK). From this, measurements of end-tidal carbon dioxide tension $\left(P \mathrm{ET}, \mathrm{CO}_{2}\right)$ were obtained. Total pulmonary resistance was measured using a catheter with a pressure transducer at the tip (CTC/6F; Gaeltec, Scotland, UK). The digitised signals (analogue-to-digital interface; 1401 Micro, Cambridge Electronic Design (C.E.D.), Cambridge, UK) were analysed using commercially written software (Spike2, C.E.D.).

Hypercapnic ventilatory response. HCVR was measured using the FENN and CRAIG [19] fixed $\mathrm{CO}_{2}$ flow-rate technique, during the application of CPAP. The addition of CPAP meant that $\mathrm{CO}_{2}$ inhalation by the standard FENN and CRAIG [19] circuit was not possible, because the $\mathrm{CO}_{2}$ would have been vented during expiration by the CPAP. To overcome this, the present authors developed the method of $\mathrm{CO}_{2}$ administration as shown in figure 1. Subjects breathed via a pneumotachometer attached to a full facemask. Distal to this was a length $(2 \mathrm{~m})$ of tubing with expiratory ports at one end (Whisper swivel; Respironics, Bognor Regis, UK) and a CPAP pump at the other (Remstar Choice LS; Respironics). The $\mathrm{CO}_{2}$ gas mixture (composition $80 \% \mathrm{CO}_{2}, 20 \%$ oxygen $\left(\mathrm{O}_{2}\right)$ ) was only delivered during inspiration. To achieve this, the constant flow of $\mathrm{CO}_{2}$ during the expiration time was collected in a reservoir. The reservoir (a glass syringe) was connected to a length of narrow tubing which fed directly into a side port on the facemask. To deliver the $\mathrm{CO}_{2}$, the syringe was opened during inspiration using a valve triggered by the flow signal. Following $5 \mathrm{~min}$ of resting air breathing, $\mathrm{CO}_{2}$ was delivered at a flow rate of

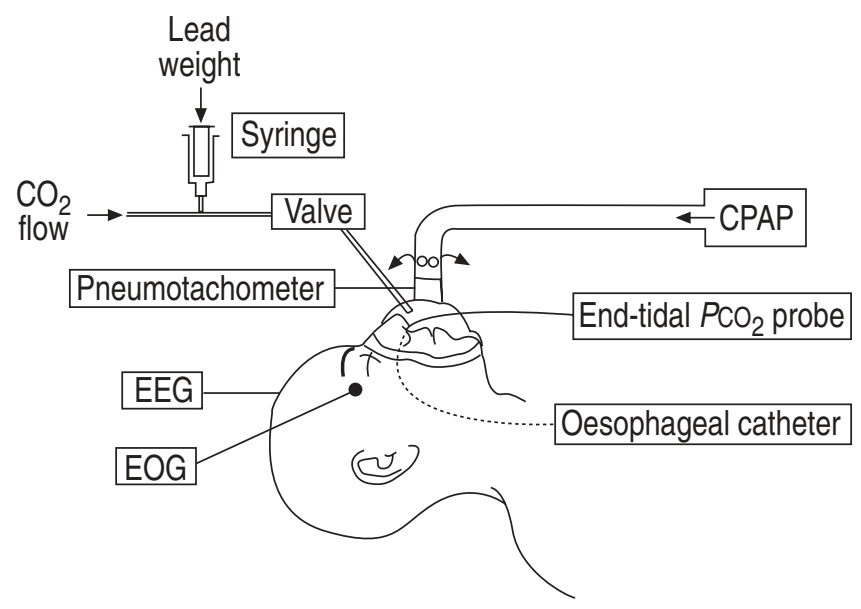

Fig. 1. - The modified breathing circuit used to measure the hypercapnic ventilatory response by the FENN and CRAIG [19] technique. CPAP: continuous positive airway pressure; $\mathrm{PCO}_{2}$ : carbon dioxide tension; EEG: electroencephalograms; EOG: electro-oculograms.
$200 \mathrm{~mL} \cdot \mathrm{min}^{-1}$ for $5 \mathrm{~min}$, followed by $400 \mathrm{~mL} \cdot \mathrm{min}^{-1}$ for a further $5 \mathrm{~min}$.

Total pulmonary resistance. An index of pleural pressure was obtained from measurements of oesophageal pressure $\left(P_{\mathrm{oes}}\right)$. Following topical anaesthesia (4\% lignocaine hydrochloride; Astra Pharmaceuticals Ltd, Hertfordshire, UK), the catheter was passed through the nostril until the tip was positioned $40 \mathrm{~cm}$ from the nares. The airflow and $P$ oes signals were used to compute a continuous on-line measurement of total pulmonary resistance $(R \mathrm{~L}$; lung tissue resistance plus the airway resistance, including the upper airway). $R \mathrm{~L}$ was analysed using previously reported techniques [14]. Briefly, $R \mathrm{~L}$ during the middle part of inspiration ( $R$ Lmidinsp) was calculated by dividing the inspiratory $R \mathrm{~L}$ signal into nine sections and averaging the middle seven.

\section{Protocol}

Hypercapnic ventilatory response study. Prior to this study, subjects deprived themselves of sleep (maximum sleep time $4 \mathrm{~h}$ ) and avoided alcohol and caffeine. First, EEG, EOG and EMG electrodes were applied and the subjects were asked to lie supine on a bed. The $\mathrm{CO}_{2}$-sampling probe was then secured and the facemask fitted. When all air leaks around the mask had been eradicated, the pneumotachometer and CPAP circuit $\left(3 \mathrm{cmH}_{2} \mathrm{O}\right)$ were attached. The wakefulness HCVR was then measured (approximately 22:00 h). Following this, the oesophageal catheter was passed and the $\mathrm{CO}_{2}$-sampling probe, facemask, pneumotachometer and CPAP were reapplied and checked for air leaks. Subjects then remained awake for $5 \mathrm{~min}$; this period was used to obtain a wakefulness baseline measurement of RLmidinsp. The subject then fell asleep (supine position). If $R$ Lmidinsp increased, CPAP was increased until $R$ Lmidinsp was reversed to wakefulness levels. Once the subject had entered stable NREM sleep and the $R$ Lmidinsp was controlled, the HCVR was measured. If an arousal occurred, $\mathrm{CO}_{2}$ administration was ended and CPAP reduced. As many interventions as possible were performed throughout the night.

Validation of techniques. A separate study was performed during wakefulness in nine elderly (66-82 yrs, six male) and nine young (21-36 yrs, five male) subjects, to ensure that the use of CPAP did not change the subject's HCVR. The HCVR was measured during the application of CPAP at 3,5 and $7 \mathrm{cmH}_{2} \mathrm{O}$ and compared to the HCVR obtained using the standard FENN and CRAIG [19] $\mathrm{CO}_{2}$ administration circuit (i.e. no CPAP). The levels of CPAP were applied in a random order. Of those participating in the validation study, seven elderly and two young subjects also participated in the HCVR study during sleep.

A further study was carried out during wakefulness to evaluate whether CPAP influenced the HCVR by inducing different changes in end-expiratory lung volume ( $\triangle E E L V)$ in the elderly and young subjects. CPAP-related changes in EELV were measured for $5 \mathrm{~min}$ in the supine position, during resting breathing and at different CPAP levels (3, 5 and $7 \mathrm{cmH}_{2} \mathrm{O}$, randomised), using respiratory inductance plethysmography (RIP; Respitrace $\mathbb{R}$, Ambulatory Monitoring, Ardsley, NY, USA). RIP bands were positioned around the chest and abdomen and calibrated using previously described techniques [20, 21]. Briefly, calibration required subjects to breathe on a rolling seal spirometer (Spiroflow; PK Morgan Ltd); respiratory frequency and tidal volume were varied during this procedure. Volume-area coefficients for chest and abdominal movements were obtained using multiple linear 
regression. At the end of the study, a validation of the calibrated RIP was performed using simple linear regression (spirometer versus RIP). For each subject, the r-value for the validation period was $>0.95$.

\section{Analysis}

Validation of techniques. At each CPAP level (i.e. 3, 5 and $7 \mathrm{cmH}_{2} \mathrm{O}$ ), the HCVR was estimated from mean expired minute ventilation $\left(V^{\prime} \mathrm{E}\right)$ and $P$ ET, $\mathrm{CO}_{2}$. Mean $V^{\prime}$ E and PET, $\mathrm{CO}_{2}$ values were calculated from breath-by-breath measurements during the last $2 \mathrm{~min}$ of each 5-min intervention (rest, and 200 and $400 \mathrm{~mL} \cdot \mathrm{min}^{-1}$ ). The effect of CPAP on lung volume was assessed from measurements of EELV made during the last 2 min of each 5-min period of CPAP $\left(3,5\right.$ and $\left.7 \mathrm{cmH}_{2} \mathrm{O}\right)$. $\triangle E E L V s$ at each CPAP level were compared to EELVs with no CPAP and expressed as a percentage of slow vital capacity (\% SVC).

Hypercapnic ventilatory response study. Sleep stage and brief cortical arousals were scored using standard criteria $[22,23]$. Mean values of $V^{\prime} \mathrm{E}, P \mathrm{ET}, \mathrm{CO}_{2}$ and $R$ Lmidinsp were calculated from breath-by-breath measurements made during the last 2 min of each 5-min intervention (rest, and 200 and $400 \mathrm{~mL} \cdot \mathrm{min}^{-1}$ ) performed during wakefulness and NREM sleep (stages II-IV) with no arousals.

Age-related differences in stability of the ventilatory pattern at sleep onset. The coefficient of variation was calculated for the breath-by-breath measurements of breath duration (ТTOT), tidal volume $(V \mathrm{~T})$ and $V^{\prime} \mathrm{E}$ during periods of sleep onset, when CPAP levels were minimal. Sleep onset was defined as a clear transition from alpha to theta activity. Four breaths pre- and post-sleep onset were selected for analysis by a researcher blinded to the respiratory traces.

\section{Statistical analysis}

The study was designed based on pre-study sample size calculations. The data are presented as mean \pm SD. The difference in the awake HCVR between the elderly and young patients has been reported as $0.104 \pm 0.052 \mathrm{~L} \cdot \mathrm{min}^{-1} \cdot \mathrm{kPa}[10]$. Assuming the magnitude of the age-related differences in the HCVR were similar during sleep, a sample size of eight would detect differences with $95 \%$ confidence intervals and 0.05 power. Likewise, in young people a mean sleep-related difference in the HCVR of $0.111 \pm 0.051 \mathrm{~L} \cdot \mathrm{min}^{-1} \cdot \mathrm{kPa}$ yielded a sample size of seven [2].

Validation of techniques. Linear regression was used to determine the HCVR slope from mean $V^{\prime} \mathrm{E}$ and $P \mathrm{ET}, \mathrm{CO}_{2}$ during rest, and at 200 and $400 \mathrm{~mL} \cdot \mathrm{min}^{-1}$, according to the equation:

$$
V^{\prime}=\mathrm{S}\left(\mathrm{PCO}_{2}-\mathrm{B}\right)
$$

where $V^{\prime}$ is gas flow, $\mathrm{PCO}_{2}$ is carbon dioxide tension, $\mathrm{S}$ is the slope of the HCVR and B is the intercept (on the $\mathrm{x}$-axis) of the line that relates ventilation and $\mathrm{PCO}_{2}$. Differences in HCVR slope and $\mathrm{x}$-axis intercept, measured with and without CPAP, within a group, were compared using a one-way repeated measures analysis of variance (ANOVA). To test for significant $\triangle E E L V$ across CPAP levels, within a group, one-way repeated measures of ANOVA were performed. To test for significant $\triangle E E L V$ between the groups, at each level of CPAP, unpaired t-tests were performed. Statistical significance was defined as $\mathrm{p} \leqslant 0.05$.
Hypercapnic ventilatory response study. The wake versus sleep group mean $R$ Lmidinsp, HCVR slope and $\mathrm{x}$-axis intercept were compared using a two-way repeated measures ANOVA. The influence of ageing on the HCVR during sleep was examined with respect to age (elderly, young) as a between factor, and state (wakefulness, NREM sleep) as a within factor.

Age-related differences in stability of the ventilatory pattern at sleep onset. The sleep-onset group means (elderly, young) for coefficient of variation for Tтот, $V \mathrm{~T}$ and $V^{\prime} E$ during periods of sleep onset (wakefulness, NREM sleep) were compared using a two-way repeated measures ANOVA.

\section{Results}

Validation of techniques. The age of the elderly subjects was $71.7 \pm 4.7$ compared to $27.9 \pm 5.9$ yrs for the younger subjects $(\mathrm{n}=9)$. The BMI was greater in the elderly group: $26.2 \pm 2.9$ versus $23.3 \pm 2.2 \mathrm{~kg} \cdot \mathrm{m}^{-2}$ (unpaired t-test, $\mathrm{p}=0.03$ ). The HCVR slopes for both the elderly and young groups, measured at CPAP levels of 3, 5 and $7 \mathrm{cmH}_{2} \mathrm{O}$ and with the standard FENN and CRAIG [19] circuit, are shown in figure 2. Neither the elderly nor young subjects showed any statistically significant differences between the HCVR slopes, measured with CPAP and the standard FENN and CRAIG [19] circuit (elderly, $p=0.85$; young, $\mathrm{p}=0.45$ ). The $\mathrm{x}$-axis intercepts, measured using CPAP levels of 3, 5 and $7 \mathrm{cmH}_{2} \mathrm{O}$ and the standard FENN and CRAIG [19] circuit, were not statistically different for either group (elderly: $2.63 \pm 2.02,2.89 \pm 1.42,2.85 \pm 1.97,3.41 \pm 0.98 \mathrm{kPa}$, $\mathrm{p}=0.34$; young: $4.40 \pm 0.63,4.62 \pm 0.86,4.31 \pm 0.76, \quad 4.55 \pm$ $0.76 \mathrm{kPa}, \mathrm{p}=0.73)$.

The $\triangle$ EELV following application of CPAP are shown in table 1 . Within both the elderly and young groups, there was a significant increase in the $\triangle \mathrm{EELV}$ with progressively greater

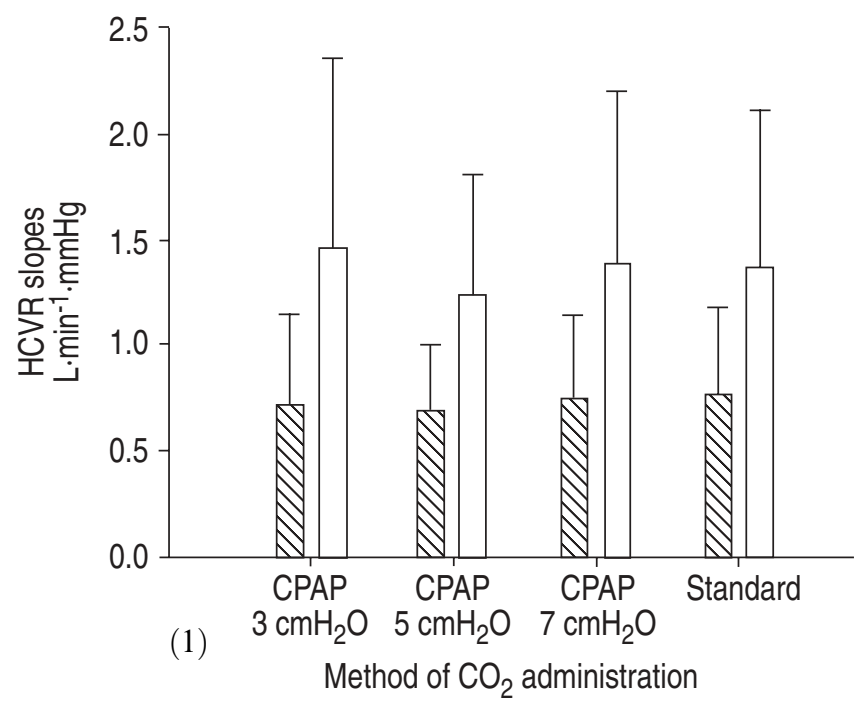

Fig. 2. - Hypercapnic ventilatory response (HCVR) slopes for elderly $(\mathbb{\nabla})$ and young $(\square)$ subjects $(n=9)$. Measurements were made using the authors' modified carbon dioxide $\left(\mathrm{CO}_{2}\right)$ administration circuit (fig. 1) at continuous positive airway pressure (CPAP) levels of 3, 5 and $7 \mathrm{cmH}_{2} \mathrm{O}$, and using the standard FENN and CRAIG [19] circuit (i.e. no CPAP). Differences in the HCVR slope, measured using each administration circuit, within each group, were compared using an analysis of variance. Note, neither elderly nor young subjects demonstrated a significant difference between HCVR slopes, measured using the authors' circuit at any level of CPAP and the standard FENN and CRAIG [19] circuit. Data are presented as mean $\pm \mathrm{SD}$. $\mathrm{kPa}=\mathrm{mmHg} \times 0.133$. 
Table 1. - Change in end-expiratory lung volume ( $\triangle E E L V)$ following application of continuous positive airway pressure (CPAP) during wakefulness

\begin{tabular}{|c|c|c|c|c|c|c|c|c|c|}
\hline & \multirow[t]{3}{*}{ Subjects $n$} & \multicolumn{4}{|c|}{$\Delta \mathrm{EELV} \mathrm{mL} \cdot \mathrm{s}^{-1}$} & \multicolumn{4}{|c|}{$\triangle \mathrm{EELV} \% \mathrm{SVC}$} \\
\hline & & \multicolumn{3}{|c|}{ CPAP pressure $\mathrm{cmH}_{2} \mathrm{O}$} & \multirow[t]{2}{*}{ p-value ${ }^{\#}$} & \multicolumn{3}{|c|}{ CPAP pressure $\mathrm{cmH}_{2} \mathrm{O}$} & \multirow[t]{2}{*}{ p-value ${ }^{\ddagger}$} \\
\hline & & 3 & 5 & 7 & & 3 & 5 & 7 & \\
\hline Elderly & 9 & $125.8 \pm 34.9$ & $240.6 \pm 87.5$ & $388.0 \pm 162.6$ & 0.001 & $4.1 \pm 0.9$ & $7.7 \pm 1.8$ & $12.3 \pm 3.8$ & 0.001 \\
\hline $\begin{array}{l}\text { Young } \\
\text { p-value }\end{array}$ & 9 & $\begin{array}{c}120.4 \pm 47.4 \\
0.79\end{array}$ & $\begin{array}{c}242.9 \pm 81.3 \\
0.95\end{array}$ & $\begin{array}{c}343.7 \pm 108.8 \\
0.51\end{array}$ & 0.001 & $\begin{array}{c}2.3 \pm 0.8 \\
0.001\end{array}$ & $\begin{array}{c}4.4 \pm 1.5 \\
0.001\end{array}$ & $\begin{array}{c}6.7 \pm 1.9 \\
0.001\end{array}$ & 0.001 \\
\hline
\end{tabular}

Data are presented as mean \pm SD unless otherwise stated. SVC: slow vital capacity. ${ }^{*}$ : p-value from analysis of variance; ${ }^{\bullet}$ : p-value from unpaired t-tests.

Table 2. - End-tidal carbon dioxide tension $\left(\mathrm{PCO}_{2}\right)$ during resting breathing and carbon dioxide administration during wakefulness and nonrapid eye movement (NREM) sleep

\begin{tabular}{|c|c|c|c|c|c|c|c|}
\hline & \multirow[t]{2}{*}{ Subjects $n$} & \multicolumn{3}{|c|}{ Wakefulness $P_{\mathrm{CO}_{2}} \mathrm{mmHg}$} & \multicolumn{3}{|c|}{ NREM sleep $\mathrm{PCO}_{2} \mathrm{mmHg}$} \\
\hline & & Rest & $200 \mathrm{~mL} \cdot \mathrm{min}^{-1}$ & $400 \mathrm{~mL} \cdot \mathrm{min}^{-1}$ & Rest & $200 \mathrm{~mL} \cdot \mathrm{min}^{-1}$ & $400 \mathrm{~mL} \cdot \min ^{-1}$ \\
\hline Elderly & 10 & $39.2 \pm 2.8$ & $43.5 \pm 3.6$ & $47.0 \pm 4.1$ & $41.2 \pm 3.9$ & $45.4 \pm 3.6$ & $51.1 \pm 3.8$ \\
\hline Young & 10 & $41.2 \pm 2.1$ & $45.3 \pm 2.0$ & $47.7 \pm 1.3$ & $44.0 \pm 3.2$ & $47.8 \pm 3.6$ & $51.9 \pm 3.7$ \\
\hline p-value & & 0.09 & 0.17 & 0.64 & 0.09 & 0.14 & 0.69 \\
\hline
\end{tabular}

Data are presented as mean \pm SD unless otherwise stated. $\mathrm{kPa}=\mathrm{mmHg} \times 0.133$. $\mathrm{p}$-Value given for unpaired $\mathrm{t}$-tests.

levels of CPAP (expressed in $\mathrm{mL}$ and as a \% SVC). Between the two groups, at each CPAP level, the magnitude of the increase was not significantly different when the $\triangle E E L V$ was expressed in $\mathrm{mL}$. However, when the increase was expressed as a $\%$ SVC it was significantly greater in the elderly compared to the young group.

Hypercapnic ventilatory response study. The age of the elderly group was $69.8 \pm 4.7$ compared to $31.0 \pm 4.1$ yrs for the young $(n=10)$. There was no significant difference in BMI between the groups $\left(25.7 \pm 3.8\right.$ versus $25.6 \pm 2.9 \mathrm{~kg} \cdot \mathrm{m}^{-1}$; unpaired t-test, $\mathrm{p}=0.91$ ).

The sleep-related increase in $P$ ET, $\mathrm{CO}_{2}$ was lower in the elderly compared to the young group (table 2 ), although the magnitude of the difference was not statistically significant between the two groups (elderly $0.27 \pm 0.27$, young $0.38 \pm$ $0.31 \mathrm{kPa}, \mathrm{p}=0.39$ ).

The use of CPAP minimised the sleep-related increase in $R$ Lmidinsp in both groups (fig. 3). The sleep-related increase in $R$ Lmidinsp was $1.6 \pm 1.2 \mathrm{cmH} \mathrm{H}_{2} \mathrm{O} \cdot \mathrm{L} \cdot \mathrm{s}^{-1}$ in the elderly and $1.2 \pm 0.8 \mathrm{cmH}_{2} \mathrm{O} \cdot \mathrm{L} \cdot \mathrm{s}^{-1}$ in the young. This small increase was statistically significant $(\mathrm{p}=0.001)$, although the magnitude of the increase was consistent between groups $(\mathrm{p}=0.40)$. The CPAP levels used were similar for the two groups (elderly $4.7 \pm 1.7 \mathrm{cmH}_{2} \mathrm{O}$, young $4.3 \pm 1.3 \mathrm{cmH}_{2} \mathrm{O}$; unpaired t-test, $\mathrm{p}=0.28)$.

During sleep, the HCVR at 200 and $400 \mathrm{~mL} \cdot \mathrm{min}^{-1}$ was carried out in seven of the 10 elderly subjects. In the remaining three, it was expressed as the slope of the line between two measurements only (at rest and $200 \mathrm{~mL} \cdot \mathrm{min}^{-1}$ ). $P$ ET, $\mathrm{CO}_{2}$ values at each flow rate of $\mathrm{CO}_{2}$, during wakefulness and sleep, are shown in table 2 .

The individual HCVR slopes for the elderly and young subjects are shown in figure 4 . In the young group, one subject had a relatively high HCVR slope, which, interestingly, persisted during sleep. There was no obvious explanation for this atypical response; however, as it was $>2$ SD beyond the mean, the authors elected to exclude this subject's data from the group analysis. The HCVR slope was: elderly $(n=10)$, wake
$0.14 \pm 0.06 \mathrm{~L} \cdot \mathrm{min}^{-1} \cdot \mathrm{kPa}$ versus sleep $0.06 \pm 0.02 \mathrm{~L} \cdot \mathrm{min}^{-1} \cdot \mathrm{kPa}$ and young $(\mathrm{n}=9)$, wake $0.19 \pm 0.07 \mathrm{~L} \cdot \mathrm{min}^{-1} \cdot \mathrm{kPa}$ versus sleep $0.10 \pm 0.04 \mathrm{~L} \cdot \mathrm{min}^{-1} \cdot \mathrm{kPa}$. The HCVR slope during sleep was $49.4 \pm 21.42 \%$ of wakefulness levels in the elderly and $53.8 \pm 19.6 \%$ in the young. These data show that the HCVR slope was reduced during sleep, irrespective of age $(p=0.001)$, and that age did not influence the magnitude of this sleeprelated reduction $(\mathrm{p}=0.58)$.

The $\mathrm{x}$-axis intercept was: elderly, wake $3.71 \pm 0.90 \mathrm{kPa}$ versus sleep $3.03 \pm 1.52 \mathrm{kPa}$ and young, wake $4.47 \pm 0.55 \mathrm{kPa}$ versus sleep $4.32 \pm 1.24 \mathrm{kPa}$. The sleep-related reduction in the $\mathrm{x}$-axis intercept seen in both groups did not reach statistical significance $(\mathrm{p}=0.06)$ and the magnitude of the reduction was consistent between the groups $(\mathrm{p}=0.21)$.

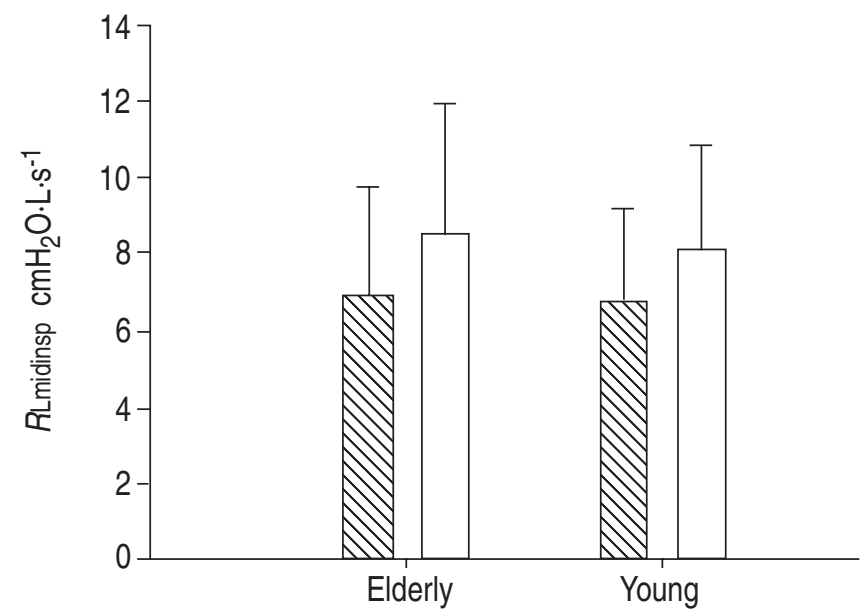

Fig. 3. - Total pulmonary resistance (RLmidinsp) for elderly and young subjects during wakefulness $(\mathbb{\mathbb { Q }})$ and sleep $(\square)$. Differences in $R$ Lmidinsp were compared with respect to age (elderly versus young) and state (wakefulness versus sleep) using analysis of variance. Data are presented as mean $\pm \mathrm{SD}$. 

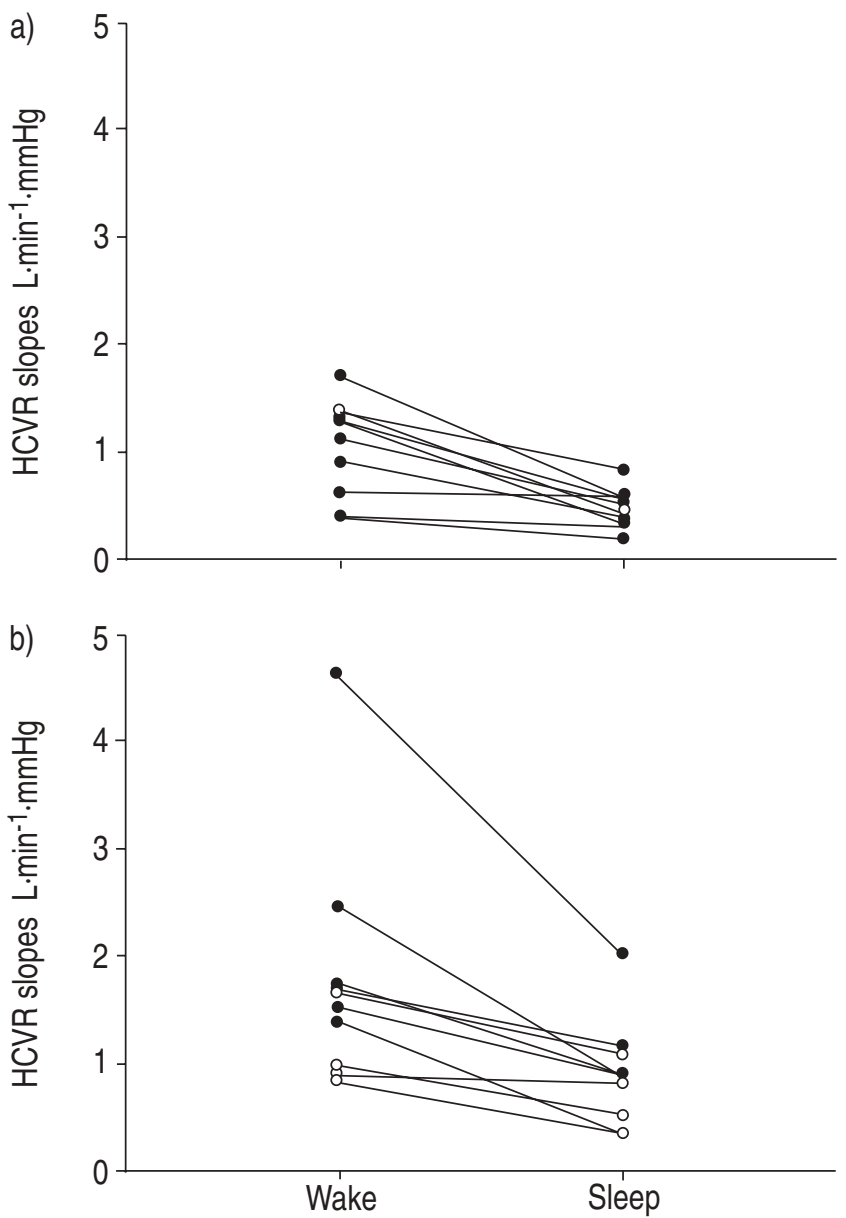

Fig. 4. - Individual hypercapnic ventilatory response (HCVR) slopes for a) elderly and $\mathrm{b})$ young subjects $(\mathrm{n}=10)$ during wakefulness and sleep. ๑: males; $\bigcirc$ : females. $\mathrm{kPa}=\mathrm{mmHg} \times 0.133$.

Age-related differences in stability of the ventilatory pattern at sleep onset. An important aim of the authors' protocol was to minimise UAR during NREM stage 2 sleep using CPAP. This approach limited the number of sleep/wake transitions that occurred when no CPAP was applied. The coefficient of variation for seven subjects in each group is shown in table 3 . There were no significant differences between the elderly and young in the stability of the ventilatory pattern at sleep onset for TTOT, $V \mathrm{~T}$ and $V^{\prime} \mathrm{E}$.

\section{Discussion}

The hypothesis that ageing results in a reduction in the magnitude of the wake-to-sleep decrease in the HCVR has been tested, using groups of elderly and young subjects. The authors have demonstrated that in a relatively small sample, the magnitude of the sleep-related decrease in the HCVR is similar in elderly and young people, when sleep state is stable, and any sleep-related increase in UAR is controlled.

The finding that in young people sleep is associated with a decrease in the HCVR confirms previous observations [1, 2]. The magnitude of the reduction was also similar. However, the findings in the elderly appear to contradict those of NAIFEH et al. [13], who found no sleep-related decrease in the HCVR (mean HCVR slopes calculated from presented data: elderly, wake 0.43 and sleep $0.42 \mathrm{~L} \cdot \mathrm{min}^{-1} \cdot \mathrm{kPa}$, young, wake 0.65 and sleep $0.43 \mathrm{~L} \cdot \mathrm{min}^{-1} \cdot \mathrm{kPa}$ ). A possible explanation of the discrepancy between the results in the current study and those of NAIFEH et al. [13] is that a relatively high HCVR during sleep could have been recorded if microarousals had occurred during their interventions, since such arousals would have been associated with hyperventilation. The Hazinski method utilised by NAIFEH et al. [13] is noninvasive and was specifically designed to reduce potential arousals. Nevertheless, the study was published in 1989, well before the classification of microarousals [23] and subsequent studies outlining the increased frequency of microarousals in the elderly $[15,24,25]$. In the present study, the authors took care to ensure that no arousals occurred during the measurement of the HCVR.

The purpose of the current study was to investigate the wake-to-sleep differences in the HCVR. However, during wakefulness the HCVR was reduced in the elderly compared to the young subjects. The magnitude of this age-related reduction was similar to previous studies, although the absolute levels in this study were lower [10-13]. Age-related decreases in lung elastic recoil $[26,27]$, chest wall compliance [26] and respiratory muscle strength [28] could account for the low awake HCVR in the elderly. Previous studies have excluded age-related alterations in muscle strength and respiratory compliance as mechanisms responsible for the reduced HCVR in the elderly [11, 29]. Clearly, further research is required to investigate the effects of age on chemosensitivity.

HCVR was measured using the FENN and CRAIG [19] steady state technique of $\mathrm{CO}_{2}$ administration. This technique was chosen because it has significant advantages. It delivers a fixed flow of $\mathrm{CO}_{2}$ rather than a fixed concentration of $\mathrm{CO}_{2}$, which ensures a constant extra load of $\mathrm{CO}_{2}$ is delivered independent of ventilation. Therefore, if the ventilation becomes variable, a constant load of $\mathrm{CO}_{2}$ will be maintained and a steady state is achieved quicker ( $<3 \mathrm{~min})$, compared to $\mathrm{CO}_{2}$ delivered at fixed concentrations [30]. This was important when measuring the HCVR in the elderly, in whom periodic breathing and fragmented sleep frequently occurs [15]. Use of the FENN and CRAIG [19] technique also allowed measurement of $\mathrm{HCVR}$ at a $\mathrm{PCO}_{2}$ level closer to the physiological range than rebreathe methods. This was advantageous in the elderly where the ventilatory response may be limited by mechanical factors at the higher levels of $\mathrm{PCO}_{2}$. Finally, it is worth noting that JACOBI et al. [31] and NAIFEH and SEVERINGHAUs [32] have shown that steady state techniques produce a lower HCVR compared to the READ

Table 3. - Coefficent of variation (CV) measurements of breath duration (TTOT), tidal volume $(V T)$ and ventilation ( $\left.V^{\prime} E\right)$ at sleep onset

\begin{tabular}{|c|c|c|c|c|c|c|c|}
\hline & \multirow[t]{2}{*}{ Subjects $n$} & \multicolumn{3}{|c|}{$\mathrm{CV}$ during pre-sleep (four alpha breaths) } & \multicolumn{3}{|c|}{$\mathrm{CV}$ during sleep (four theta breaths) } \\
\hline & & ТTOT $\%$ & $V \mathrm{~T} \%$ & $V^{\prime} \mathrm{E} \%$ & Ттот $\%$ & $V \mathrm{~T} \%$ & $V^{\prime} \mathrm{E} \%$ \\
\hline Young & 7 & $7.7 \pm 9.29$ & $13.1 \pm 12.20$ & $12.4 \pm 9.64$ & $8.9 \pm 10.60$ & $13.6 \pm 17.22$ & $10.4 \pm 7.54$ \\
\hline Elderly & 7 & $8.0 \pm 5.40$ & $10.1 \pm 8.08$ & $13.5 \pm 8.24$ & $6.4 \pm 4.05$ & $13.0 \pm 10.23$ & $12.7 \pm 7.23$ \\
\hline
\end{tabular}

Data are presented as mean $\pm \mathrm{SD}$. 
[33] rebreathing technique and the HAZINSKI et al. [34] method. This is consistent with the findings in the present study of lower HCVR slopes, in both elderly and young subjects, compared to those previously reported [10-13].

\section{Physiological factors that may influence the HCVR}

The authors have previously shown UAR during sleep to be greater in the elderly compared to the young [14]. As sleeprelated increases in UAR would reduce the HCVR, in the present study, any sleep-related increases in UAR were controlled using CPAP. The authors' validation study demonstrated that changes in lung volume associated with the application of CPAP did not affect the HCVR. Interestingly, the level of CPAP required to abolish the sleep-related increase in resistance was similar in both groups, despite the higher resistance in the elderly. A preliminary study [35], carried out in the authors' laboratory supports this observation. Elderly CPAP users required a lower level of CPAP to reverse airflow limitation compared to younger people with a similar level of disease severity.

Previous investigators have demonstrated females to have a significantly lower HCVR than males [36]. During the current study both male and female subjects were recruited. Overall, the young females did have a reduced HCVR compared to the young males during both wakefulness and sleep (female, wake $0.14 \pm 0.05$ and sleep $0.09 \pm 0.04 \mathrm{~L} \cdot \mathrm{min}^{-1} \cdot \mathrm{kPa}$ and male, wake $0.23 \pm 0.06$ and sleep $0.11 \pm 0.04 \mathrm{~L} \cdot \mathrm{min}^{-1} \cdot \mathrm{kPa}$; fig. 4). Although this would have reduced the overall difference between the elderly and young subjects, importantly it would not have affected the magnitude of the sleep-related reduction.

Sleep deprivation has been found to have no effect on the HCVR [37]. Therefore, this is unlikely to have affected the results in the present study. However, the HCVR does vary with sleep stage and duration; the lowest slopes are measured during rapid eye movement (REM) sleep at the end of the night [38]. To overcome this, the authors performed the HCVR during stable NREM sleep, between 01:00 and 03:00 h. The HCVR also varies with circadian phase with the nadir of the slope occurring between 14:00 and 20:00 h [39]. These hours were avoided by performing the wakefulness measurements immediately before the subject went to bed, at 22:00 h.

Previous studies have shown a decrease in cerebral blood flow with increasing age $[40,41]$. This decrease would result in a higher prevailing $\mathrm{PCO}_{2}$ at the central chemoreceptors for a given level of carbon dioxide arterial tension $\left(\mathrm{Pa}_{\mathrm{a}} \mathrm{CO}_{2}\right)$ in the elderly. However, there is no change in the cerebrovasodilator response to $\mathrm{CO}_{2}$ with increasing age in males [42], suggesting that although the set point at the central chemoreceptors may differ between the two groups, the age-related reduction in the HCVR is unlikely to be accounted for by differences in cerebral blood flow.

\section{Mechanisms of CSA in the elderly}

The findings in the current study indicate that age-related changes in the HCVR are unlikely to contribute to the increased prevalence of CSA in the elderly. However, they do not preclude an age-related change in the distance between the hypocapnic apnoeic thresholds relative to the wake to sleep increase in $\mathrm{PET}, \mathrm{CO}_{2}$. In $\mathrm{CHF}$ patients with CSA, the small sleep-related increase in $P \mathrm{ET}, \mathrm{CO}_{2}$ results in a narrowing between the sleeping $P$ ET, $\mathrm{CO}_{2}$ and the apnoeic threshold, which predisposes the development of apnoea and breathing instability at sleep onset [43]. The relatively small sleep-related increase in $P \mathrm{ET}, \mathrm{CO}_{2}$ in the elderly suggests that similar mechanisms may contribute to the increased prevalence of CSA in this group. Although the authors did not observe differences in the variability of breathing at sleep onset between elderly and young people.

Another factor, which may predispose the elderly to CSA, is the age-related increase in arousal frequency [15, 24, 25]. Arousal from sleep leads to hyperventilation and the resulting hypocapnia (and reduced central respiratory drive) could promote a CSA following sleep resumption. The correlation between fluctuations in EEG frequency and changes in tidal volume in elderly people support this idea [44]. In the present study, sleep onset did not produce significant periodic or unstable breathing in elderly or young people. However, these findings should be interpreted with caution due to the paucity of data in the relatively small sample of this study. The authors therefore speculate that in the elderly, differences in arousal frequency and a relatively large sleep-to-wake difference in pharyngeal resistance [14] are therefore likely explanations for the increased occurrence of CSA.

\section{Conclusion}

The current study shows that ageing per se does not influence the magnitude of the sleep-related decrease in the HCVR. These findings, albeit in a small sample, do not support the suggestion that CSA and periodic breathing in the elderly are caused by a relatively high ventilatory chemoreflex loop gain during sleep. An alternative explanation for the increased prevalence of sleep apnoea in the elderly is that the incidence of diseases that are associated with CSA is higher in the elderly, e.g. the annual incidence of heart failure doubles for every decade over the age of 45 yrs [45] and $\sim 45 \%$ of all heart failure patients have CSA [4].

In one of the most comprehensive studies of sleep apnoea in the elderly, involving randomly selected, independently living subjects (65-95 yrs), the prevalence of sleep apnoea, defined as an apnoea index of $\geqslant 5$ events $\cdot \mathrm{h}^{-1}$, was $24 \%$ [8]. Elderly people, randomly selected from new hospital admissions and nursing homes, were also studied and in these groups, the apnoea index was $33 \%$ and $42 \%$, respectively [46]. The higher prevalence of sleep apnoea in the hospital and nursing home patients, compared to elderly people living independently, may be attributed to the higher incidence of health problems (such as heart failure) and medication use. More recently, the prevalence of sleep apnoea (apnoea/hypopnoea index of $\geqslant 10$ events $\cdot \mathrm{h}^{-1}$ ) was reported to be $24 \%$ in a population of elderly males living independently, aged 65-100 yrs, compared to $3 \%$ in a younger population, aged 20-44 yrs [9]. Taken together, these studies support the idea that sleep apnoea is common in healthy elderly people $(\sim 24 \%)$, rising to $30-40 \%$ in elderly people with co-related diseases that render them unable to look after themselves. The current study shows that further investigations are required to determine the exact causes of the increased prevalence of sleepdisordered breathing in otherwise healthy elderly people.

\footnotetext{
Acknowledgements. The authors gratefully acknowledge D.R. Corfield for his assistance setting up the carbon dioxide breathing circuit and $\mathrm{K}$. Murphy for his assistance with the writing of the analysis scripts.
}

\section{References}

1. Bulow K. Respiration and wakefulness in man. Acta Physiol Scand 1963; 59: 1-110.

2. Douglas NJ, White DP, Weil JV, Pickett CK, Zwillich CW. 
Hypercapnic ventilatory response in sleeping adults. Am Rev Respir Dis 1982; 126: 758-776.

3. Khoo MC. Determinants of ventilatory instability and variability. Respir Physiol 2000; 122: 167-182.

4. Javaheri S. A mechanism of central sleep apnoea in patients with heart failure. $N$ Engl J Med 1999; 341: 949-954.

5. Xie A, Rutherford R, Rankin F, Wong B, Bradley TD. Hypocapnia and increased ventilatory responsiveness in patients with idiopathic central sleep apnoea. Am J Respir Crit Care Med 1995; 152: 1950-1955.

6. Carskadon MA, Dement WC. Respiration during sleep in the aged human. J Gerontol 1981; 36: 420-423.

7. Krieger J, Turlot JC, Mangin P, Kurtz D. Breathing during sleep in normal young and elderly subjects: hypopneas, apnoeas, and correlated factors. Sleep 1983; 6: 108-120.

8. Ancoli-Israel S, Kripke DF, Klauber MR, Mason WJ, Fell R, Kaplan O. Sleep-disordered breathing in communitydwelling elderly. Sleep 1991; 14: 486-495.

9. Bixler EO, Vgontzas AN, Ten Have T, Tyson K, Kales A. Effects of age on sleep apnoea in men: I. Prevalence and severity. Am J Respir Crit Care Med 1998; 157: 144-148.

10. Kronenberg RS, Drage CW. Attenuation of the ventilatory and heart rate responses to hypoxia and hypercapnia with ageing in normal men. J Clin Invest 1973; 52: 1812-1819.

11. Peterson DD, Pack AI, Silage DA, Fishman AP. Effects of ageing on ventilatory and occlusion pressure responses to hypoxia and hypercapnia. Am Rev Respir Dis 1981; 124: 387-391.

12. Brischetto MJ, Millman RP, Peterson DD, Silage DA, Pack AI. Effect of ageing on ventilatory response to exercise and $\mathrm{CO}_{2}$. J Appl Physiol 1984; 56: 1143-1150.

13. Naifeh KH, Severinghaus JW, Kamiya J, Krafft M. Effect of ageing on estimates of hypercapnic ventilatory response during sleep. J Appl Physiol 1989; 66: 1956-1964.

14. Browne HAK, Adams L, Simonds AK, Morrell MJ. Impact of age on breathing and resistive pressure in people with and without sleep apnoea. J Appl Physiol 2001; 90: 1074-1082.

15. Browne HAK, Adams A, Simonds AK, Morrell MJ. The impact of sleep apnoea on arousals from sleep and associated daytime sleepiness is not age dependent (abstract). Thorax 2000; 55: A53.

16. Henke KG, Dempsey JA, Kowitz JM, Skatrud JB. Effects of sleep-induced increases in upper airway resistance on ventilation. J Appl Physiol 1990; 69: 617-624.

17. Morrell MJ, Harty HR, Adams L, Guz A. Changes in total pulmonary resistance and $\mathrm{PCO}_{2}$ between wakefulness and sleep in normal human subjects. J Appl Physiol 1995; 78: 1339-1349.

18. Roberts CM, MacRae KD, Winning AJ, Adams L, Seed WA. Reference values and prediction equations for normal lung function in a non-smoking white urban population. Thorax 1991; 46: 643-650.

19. Fenn WO, Craig AB. Effect of $\mathrm{CO}_{2}$ on respiration using a new method of administering $\mathrm{CO}_{2}$. J Appl Physiol 1963; 18: $1023-1024$.

20. Corfield DR, Morrell MJ, Guz A. The nature of breathing during hypocapnia in awake man. Respir Physiol 1995; 101: 145-159.

21. Morrell MJ, Harty HR, Adams L, Guz A. Breathing during wakefulness and NREM sleep in humans without an upper airway. J Appl Physiol 1996; 81: 274-281.

22. Rechtschaffen A, Kales A. A manual of standardized terminology, techniques and scoring system for sleep stages of human subjects. Publication no. 204. Bethesda, MD, National Institute of Health, 1968.

23. Task Force of the American Sleep Disorders Association. EEG arousals: scoring rules and examples: a preliminary report from the Sleep Disorders Atlas Task Force of the American Sleep Disorders Association. Sleep 1992; 15: 173-184.
24. Mathur R, Douglas NJ. Frequency of EEG arousals from nocturnal sleep in normal subjects. Sleep 1995; 18: 330-333.

25. Boselli M, Parrino L, Smerieri A, Terzano MG. Effect of age on EEG arousals in normal sleep. Sleep 1998; 21: 351-357.

26. Mittman C, Edelman NH, Norris AH, Shock NW. Relationship between chest wall and pulmonary compliance and age. J Appl Physiol 1965; 20: 1211-1216.

27. Turner JM, Mead J, Wohl ME. Elasticity of human lungs in relation to age. J Appl Physiol 1968; 25: 664-671.

28. Black LF, Hyatt RE. Maximal respiratory pressures: normal values and relationship to age and sex. Am Rev Respir Dis 1969; 99: 696-702.

29. Rubin S, Tack M, Cherniack NS. Effect of ageing on respiratory responses to $\mathrm{CO}_{2}$ and inspiratory resistive loads. J Gerontol 1982; 37: 306-312.

30. Saunders KB, Partridge MR, Watson AC. Inhalation of $\mathrm{CO}_{2}$ by a constant inflow technique at rest and during exercise. Amsterdam, Elsevier Biomedical Press, 1980.

31. Jacobi MS, Patil CP, Saunders KB. Comparison of transient steady state and rebreathing methods of measuring the ventilatory response to carbon dioxide in man. $J$ Physiol 1989; 411: 85-96.

32. Naifeh KH, Severinghaus JW. Validation of a maskless $\mathrm{CO}_{2}$-response test for sleep and infant studies. $J$ Appl Physiol 1988; 64: 391-396.

33. Read DJC. A clinical method for assessing the ventilatory response to carbon dioxide. Aust Ann Med 1967; 1: 20-32.

34. Hazinski TA, Severinghaus JW, Marin MS, Tooley WH. Estimation of ventilatory response to carbon dioxide in newborn infants using skin surface blood gas electrodes. J Pediatr 1984; 105: 389-393.

35. Browne HAK, Simonds AK, Adams L, Morrell MJ. Why do elderly apnoeic patients require a lower level of CPAP to reverse their apnoea/hypopnea index? (abstract) Am J Respir Crit Care Med 2002; 165: A410.

36. Patrick JM, Howard A. The influence of age, sex, body size and lung size on the control and pattern of breathing during $\mathrm{CO}_{2}$ inhalation in Caucasians. Respir Physiol 1972; 16: 337-350.

37. Spengler CM, Shea SA. Sleep deprivation per se does not decrease the hypercapnic ventilatory response in humans. Am J Respir Crit Care Med 2000; 161: 1124-1128.

38. Schafer T. Variability of vigilance and ventilation: studies on the control of respiration during sleep. Respir Physiol 1998; 114: $37-48$.

39. Spengler CM, Czeisler CA, Shea SA. An endogenous circadian rhythm of respiratory control in humans. J Physiol 2000; 526: 683-694.

40. Davis SM, Ackerman RH, Correia JA, et al. Cerebral blood flow and cerebrovascular $\mathrm{CO}_{2}$ reactivity in stroke-age normal controls. Neurology 1983; 33: 391-399.

41. Reich T, Rusinek H. Cerebral cortical and white matter reactivity to carbon dioxide. Stroke 1989; 20: 453-457.

42. Kastrup A, Dichgans J, Niemeier M, Schabet M. Changes of cerebrovascular $\mathrm{CO}_{2}$ reactivity during normal ageing. Stroke 1998; 29: 1311-1314.

43. Xie A, Skatrud JB, Puleo DS, Rahko PS, Dempsey JA. Apnoea-hypopnea threshold for $\mathrm{CO}_{2}$ in patients with congestive heart failure. Am J Respir Crit Care Med 2002; 165: $1245-1250$.

44. Pack AI, Silage DA, Millman RP, Knight H, Shore ET, Chung DC. Spectral analysis of ventilation in elderly subjects awake and asleep. J Appl Physiol 1988; 64: 1257-1267.

45. Cowie MR, Wood DA, Coats AJ, et al. Incidence and aetiology of heart failure; a population-based study. Eur Heart J 1999; 20: 421-428.

46. Ancoli-Israel S, Klauber MR, Kripke DF, Parker L, Cobarrubias M. Sleep apnoea in female patients in a nursing home. Increased risk of mortality. Chest 1989; 96: 1054-1058. 